\title{
Maternal' Awareness of Antenatal Care on Impact of Mothers' and Newborn Health in Bangladesh
}

\author{
Manju Ara Khatun', Shanzida Khatun² \\ ${ }^{1}$ Dhaka Nursing College, Dhaka, Bangladesh \\ ${ }^{2}$ National Institute of Advance Nursing Education and Research (NIANER), Mugda, Bangladesh \\ Email: manjuarakhatun@yahoo.com
}

How to cite this paper: Khatun, M.A. and Khatun, S. (2018) Maternal' Awareness of Antenatal Care on Impact of Mothers' and Newborn Health in Bangladesh. Open Journal of Nursing, 8, 102-113. https://doi.org/10.4236/ojn.2018.81009

Received: November 20, 2017 Accepted: January 28, 2018

Published: January 31, 2018

Copyright $\odot 2018$ by authors and Scientific Research Publishing Inc. This work is licensed under the Creative Commons Attribution International License (CC BY 4.0).

http://creativecommons.org/licenses/by/4.0/

\begin{abstract}
Background: Globally, maternal and infant morbidity and mortality is a serious public health problem. Maternal mortality rate in Bangladesh is 176 per lack live births which remain high as Government set target to be achieved by 2016. Antenatal care is extremely important health care service for the mothers' and unborn fetus during pregnancy. It is well recognized that good antenatal care improves maternal, perinatal and neonatal outcomes. Objective: To identify the maternal awareness of antenatal care on impact of mothers' and newborn health in Bangladesh. Methods: The study was conducted by using descriptive and cross-sectional design. This study was approved by the appropriate authority and informed consent forms were obtained from the participants. Two hundred forty-one of rural and two hundred one urban mothers completed three sets of questionnaires: 1) Socio-demographic, 2) Maternal Awareness and 3) Impact of Awareness. Content validity was done by the experts and internal consistency of these instruments was satisfactory with Cronbach's alpha over 0.74. Result: The average awareness scores of rural and urban mothers were $18.54 \pm 2.77$ and $19.69 \pm 2.16$ respectively. The mean scores of impact on rural and urban mothers were $9.41 \pm 2.13$ and $9.39 \pm 2.25$ respectively. Maternal' awareness of antenatal care; impact of mothers' and newborn health were found statistically significant $(\mathrm{t}=68.54, \mathrm{p}<0.001)$ and $(\mathrm{t}$ $=59.11, \mathrm{p}<0.001)$ different among rural and urban mother's. It was observed that maternal' awareness of antenatal care and impact of mothers' and newborn health were significantly difference between rural and urban mothers' $\left(x^{2}\right.$ $=211.869, \mathrm{p} 0.004$ and $\left(x^{2}=157.772, \mathrm{p} 0.002\right.$ respectively). Conclusions: The findings indicated that maternal' awareness of antenatal care on impact of mothers' and newborn health was statistically significant different between
\end{abstract}


rural and urban mothers'. Further intervention study is needed to evaluate the effect of intervention on maternal and child health outcomes that represent the whole population.

\section{Keywords}

Awareness, Impact, Mothers', Newborns, Antenatal Care

\section{Introduction}

Globally, maternal mortality and morbidity is a serious public health problem. Every year approximately 303,000 women die while pregnant and within 42 days after termination of pregnancy [1] [2]. Of these $99 \%$ of 800 maternal deaths per day occur in developing countries [3]. Each year 2.7 million newborns died within the first 28 days of life and 2.6 million babies' stillbirths [2], of which approximately $45 \%$ occur during labor and birth. In Bangladesh, the rate of maternal mortality, neonatal mortality, and stillbirth are 176/100,000 live births, 24/1000 live births, and 36/1000 births respectively [4], [5], [6], [7]. The low birth weight is $33 / 1000$ live births [6]. Moreover a study found $22.6 \%$ low birth weight [8]. The overwhelming majority of these deaths could have been prevented [9] [10] [11].

The leading causes of maternal mortality are postpartum hemorrhage $(31 \%)$, eclampsia/pre-eclampsia (20\%), delayed and obstructed labour (7\%), abortion (1\%), other direct cause (5\%) and indirect cause (35\%) [12]. Maternal education, lack of access of antenatal care is significant associated with increased risk of stillbirth(s). Low birth weight (LBW) is closely associated with fetal and neonatal mortality and morbidity [13]. Premature birth, poor nutritional status, inadequate nutritional intake during pregnancy, and poverty are the major causes of low birth weight babies [14] and low birth weight is strongly associated with neonatal mortality and developmental problem in childhood and adulthood [15], type 2 diabetes, hypertension and cardiovascular disease in the later part of their life [8]. These deaths and complications have to occur especially due to lack of proper antenatal care or inadequate management of pregnancy [16] [17] [18].

Antenatal care (ANC) is an effective tool to reduce both infant and maternal mortality and morbidity. The principle of ANC is to provide advice, education, reassurance, and support; to address and treat the minor problems of pregnancy; and to provide effective screening during the pregnancy [19] [20]. It is well recognized that good antenatal care improves maternal, perinatal and neonatal outcomes. Ministry of Health and Family Welfare (MOHFW) initiated the Health, Population, and Nutrition Sector Development Program (HPNSDP) for five years, from July 2011 to June 2016. Antenatal care service is one of the programs which is working toward achieving Millennium Development Goals 4 and 5 (child mortality and maternal health) [21]. The target indicators of MDGs 4 and 5 includes reduce maternal mortality rate from 194/100000 live births to 
$<143 / 1000000$ live births; neonatal mortality rate from 32/1000 live births to $21 / 1000$ live births; and infant mortality rate from 43/1000 live births to $31 / 1000$ live births will need to achieved by 2015 [22] [23] [24]. ANC is one of the programs which can achieve the Millennium Development Goals 4 \& 5. So it is needed to see the maternal awareness about antenatal care whether antenatal care services effectively achieved.

There was no previous published study in Bangladesh. The study intended to identify the maternal awareness of antenatal care on impact of mother's and newborn health. The findings can be played an important role to the nurse midwives to provide adequate information to the pregnant mother's that can help to increase maternal awareness for good health of mother's and newborn which may help in achieving the Sustainable Millennium Development Goals (SDGs) 4.

\section{Conceptual framework}

The conceptual framework of this study guided by the literature on Antenatal care, Millennium Development goals progress report of Government of the Republic of Bangladesh 2012 and World Health Organization (WHO) Country Cooperation Strategy Bangladesh 2014-2017 to developed conceptual frame work. In this study mainly three domain were used. This includes 1) socio-demographic refers to age, religion, education, occupation of mothers', monthly family income, number of family member, number of children, gestational age and condition during pregnancy which are affect of mothers' awareness, and impact of mothers' and newborn health; 2) awareness refers to knowing about meaning and important of antenatal care, ANC visits, colostrums, benefits of colostrums, breastfeeding, benefit of colostrums and breastfeeding, duration of exclusive breastfeeding, length of breastfeeding with complementary feeding, nutrition during pregnancy, place of delivery and postnatal care which are influence to impact of mothers' and newborn health; and 3) impact refers to outcome of mothers' awareness on antenatal care regarding place of delivery, birth attendants, face any problem during delivery, condition of mothers' during and after delivery, birth weight of newborn, condition of baby during and after birth, type of first feed, time of colostrums feeding and exclusive breastfeeding after birth which influence by the socio-demographic and maternal' awareness of ANC.

\section{Methods}

\subsection{Setting and Participants}

Participants were recruited from Dhaka Medical College Hospital (DMCH) and Sir Salimullah Medical College Hospital (SSMCH), Mitford, Dhaka, Bangladesh. Mother's of this study were postpartum mothers'. This study was conducted from May 2014 to October 2014 at inpatients department for maternal and child birth care delivery. The sample size was estimated in this study by using statistical formula.

$$
N=\frac{Z 2 p(1-p)}{d 2}=
$$




$$
N=\frac{(1.96)^{2}(0.5)(0.5)}{(0.05)^{2}}=384.16
$$

However, for $15 \%$ attrition the final sample size for data analysis However, for $15 \%$ attrition the final sample size for data analysis was four hundred forty two mothers. Two hundred forty one for rural and two hundred one for urban mothers' as considered their living place. A systematic random sampling method was used to recruit the eligible subjects in this study. All Mothers' met the following inclusion criteria: a) gave childbirth at least one day before; b) agreed to participate, c) both healthy and unhealthy mothers'. Disagreed to participate of mothers' were excluded from this study. According to section criteria, systematic random sampling techniques were made by distribution of patients' bed. Two alternative bed selected to prevent bias. If the selected occupied bed unable to meet the criteria then next occupied bed were included for sampling.

\subsection{Measure}

Data were collected by using three questionnaires: 1) The Demographic data questionnaire, 2) Awareness questionnaire and 3) Impact questionnaire.

\section{The demographic data questionnaire}

The Demographic Data Questionnaire was designed by the researcher based on the literature review. The characteristics of mothers' consisted of age, religion, educational level, occupation, monthly family income, living place, number of family member, number of children, length of pregnancy and condition during pregnancy.

\section{Awareness related questionnaire}

Awareness refers to knowledge related questionnaire was developed by the researcher based on the literature review. It consisted of meaning of antenatal care, importance of antenatal care, number of ANC received, meaning of colostrums, benefit of colostrums, meaning of exclusive breastfeeding, duration of exclusive breastfeeding, advantages of breastfeeding, breastfeeding continue with complimentary feeding, nutrtion during pregnancy, place of delivery, and postnatal care.

\section{Impact related questionnaire}

Impact related questionnaire was developed by the researcher based on the literature review. It consisted of place of delivery; face any problem during child birth, mothers' condition during and after child birth, birth weight of newborn, babies' condition during and after birth, type of first feeding after birth, time of colostrums, exclusive breastfeeding after birth.

\subsection{Validity and Reliability}

The content validity of the instruments was completed by experts from obstratic \& gynecologists, pediatrics, and nursing specialists. The researcher reviewed and revised all instruments using the experts' suggestions. Pilot study was conducted with thirty postpartum mothers who had the same inclusion criteria as the subjects of this study. The internal consistency and reliability of the instruments 
were tested using Cronbach's alpha coefficient, with an acceptable level of at least 0.70 [25]. In this study Cronbach's alpha coefficients was satisfactory for the study variables.

\subsection{Data Collection}

A descriptive approach was used. Data were collected through self-report questionnaires. After getting permission from the Directors of DMCH and SSMC Mitford Hospital, the researcher met with the charge nurse of the selected ward and the participants who met the inclusion criteria. The researcher introduced herself and briefly explained the purpose of the study and explained informs consent and that mother's had a right to refuse to participate in the study at any time. Then the researcher asked participants to provide answers in accordance with the questions being asked. The individual interview was conducted for 30 minutes.

\subsection{Data Analysis}

Both descriptive and inferential statistics were used to analyze the data. Descriptive statistics were used to analyze the characteristics of mother's. The differences between maternal awareness of antenatal care on impact of mother's and newborn health were analyzed using chi-square test. Maternal awareness and impact of mother's and newborn health were analyzed by using descriptive statistics and correlation between awareness of antenatal care and impact of mother's and newborn health analyzed by t-test.

\subsection{Ethical Consideration}

This study was a part of doctoral thesis and was an own pay distance learning (American World University, USA). Permission was taken from appropriate authority. Then researcher took written permission from Director of DMCH and SSMCH, Mitford, Dhaka for data collection. Written consent obtained from the mothers'. All mothers' were well informed about the study purposes and methods. Mothers also informed that there was no risk for giving information; no obligation to attend this study; can withdraw any time; and confidentiality strictly maintain.

\section{Result}

\subsection{Participants}

A total of four hundred forty two postnatal mothers' gave child birth who participated in this study. Among them 241 mothers' were living in rural area and 201 mothers' in urban area. The mean age of 241 rural and 201 urban postnatal mothers' were $24.77 \pm 4.05$ and $24.77 \pm 4.5$ years (range, 18 - 38) respectively. Most of the rural and urban mothers' had below college education $(78.4 \%$, $65.2 \%)$ and majority of mothers in both areas were Muslim (80.5\%, 87.1\%). A large number of mothers' had no paid employment (rural 96.7\%, urban 93.0\%). 
The average monthly family income of mothers in both areas were $9153.53 \pm$ 4302 Taka and $9970.15 \pm 5210.480$ Taka respectively that were bellow than national standard. In Bangladesh the average monthly household income was 31883 Taka (US dollars \$1073) in 2015 [26]. Majority (60.2\%) of rural mothers' was join family and $67.2 \%$ urban mothers' was nuclear family, more than half of rural mothers' had $\geq 2$ children (60.6) and $50.2 \%$ had $<2$ children in urban mothers'. $64.3 \%$ rural and $60.2 \%$ urban mothers' family member were 4 - 6 persons. A majority $84.6 \%$ rural and $76.6 \%$ urban mothers' duration of pregnancy was 37 weeks and more, and majority had no complication $97.5 \%$ rural and 98.0\% urban mothers' during pregnancy (Table 1).

\subsection{Differences in Rural Maternal Awareness of Antenatal Care and Impact of Mothers' and Newborn Health and Demographic Characteristics}

Table 2 shows the differences in maternal awareness of antenatal care and impact of mothers' and newborn health according to demographic characteristics. Rural mothers' awareness was statistically significantly different by monthly family income $(\mathrm{t}=4.30, \mathrm{p}<0.001)$. Impact of rural mothers' and newborn health was statistically highly significant different by the length of pregnancy $(\mathrm{t}=$ $3.768, \mathrm{p}<0.001)$ and complication during pregnancy $(\mathrm{t}=-2.607, \mathrm{p} 0.010)$.

Table 1. General characteristic of rural and urban mothers'.

\begin{tabular}{|c|c|c|c|c|c|c|c|}
\hline \multirow{2}{*}{ Characteristics } & \multirow{2}{*}{ Categories } & \multicolumn{3}{|c|}{ Rural Mothers' $(\mathrm{N}=241)$} & \multicolumn{3}{|c|}{ Urban Mothers' $(\mathrm{N}=201)$} \\
\hline & & $\mathrm{N}$ & $\%$ & $\mathrm{M} \pm \mathrm{SD}$ & $\mathrm{N}$ & $\%$ & $\mathrm{M} \pm \mathrm{SD}$ \\
\hline \multirow{2}{*}{ Age (years) } & $<26$ & 131 & 54.4 & $24.77 \pm 4.05$ & 124 & 61.7 & $24.77 \pm 4.56$ \\
\hline & $\geq 26$ & 110 & 45.6 & & 77 & 38.3 & \\
\hline \multirow{3}{*}{ Education level } & Illiterate & 37 & 15.4 & & 38 & 18.9 & \\
\hline & $<$ College & 189 & 78.4 & & 131 & 65.2 & \\
\hline & College + & 15 & 6.2 & & 32 & 15.9 & \\
\hline \multirow{2}{*}{ Religion } & Islam & 194 & 80.5 & & 175 & 87.1 & \\
\hline & Hindu & 47 & 19.5 & & 26 & 12.9 & \\
\hline \multirow{2}{*}{ Employment status } & Employed & 8 & 3.3 & & 14 & 7.0 & \\
\hline & Unemployed & 233 & 96.7 & & 187 & 93.0 & \\
\hline \multirow{2}{*}{ Monthly family income (TK.)* } & $<10000$ & 25 & 10.4 & $9153.53 \pm 4302.528$ & 12 & 6.0 & $9970.15 \pm 5210.48$ \\
\hline & $\geq 10000$ & 216 & 89.6 & & 189 & 94.0 & \\
\hline \multirow{2}{*}{ Type of family } & Single & 96 & 39.8 & & 135 & 67.2 & \\
\hline & Joint & 145 & 60.2 & & 66 & 32.8 & \\
\hline \multirow{2}{*}{ Number of children } & $<2$ & 94 & 39.0 & $1.61 \pm 0.496$ & 101 & 50.2 & $1.59 \pm 0.71$ \\
\hline & $\geq 2$ & 147 & 61.0 & & 100 & 49.8 & \\
\hline \multirow{2}{*}{ Number of family member } & $<4$ & 43 & 17.8 & $2.06 \pm 0.711$ & 59 & 29.3 & $4.02 \pm 1.23$ \\
\hline & $\geq 4$ & 198 & 82.2 & & 142 & 70.7 & \\
\hline \multirow{2}{*}{ Length of pregnancy } & $<37$ wks & 36 & 14.9 & $37.17 \pm 0.84$ & 47 & 23.4 & $37.4 \pm 1.18$ \\
\hline & $\geq 37$ wks & 205 & 85.1 & & 154 & 76.6 & \\
\hline \multirow{2}{*}{ Complication during pregnancy } & Yes & 6 & 2.5 & & 4 & 2.0 & \\
\hline & No & 235 & 97.5 & & 197 & 98.0 & \\
\hline
\end{tabular}

Notes: ${ }^{*} \mathrm{BDT}=100=\mathrm{USD}=(\$ 1.21)$. 
Table 2. Differences in awareness of antenatal care and impact of rural mothers' and newborn health according to demographic characteristics $(\mathrm{N}=241)$.

\begin{tabular}{|c|c|c|c|c|c|}
\hline \multirow{2}{*}{ Demographic characteristics } & \multirow{2}{*}{ Categories } & \multicolumn{2}{|c|}{ Maternal Awareness } & \multicolumn{2}{|c|}{ Impact of mothers' and newborn health } \\
\hline & & $\mathrm{M} \pm \mathrm{SD}$ & $\mathrm{t} / \mathrm{x}^{2}(\mathrm{p})$ & $\mathrm{M} \pm \mathrm{SD}$ & $\mathrm{t} / \mathrm{x}^{2}(\mathrm{p})$ \\
\hline \multirow{2}{*}{ Age of mothers } & $<26$ yrs & $24.60 \pm 2.93$ & $-0.806(0.421)$ & $15.03 \pm 1.95$ & $1.222(0.223)$ \\
\hline & $\geq 26 \mathrm{yrs}$ & $24.90 \pm 2.72$ & & $14.73 \pm 1.76$ & \\
\hline \multirow{2}{*}{ Education } & Illiterate & $25.02 \pm 3.43$ & $0.664(0.516)$ & $14.66 \pm 1.46$ & $-0.933(0.352)$ \\
\hline & Below college & $24.72 \pm 2.76$ & & $14.97 \pm 14.97$ & \\
\hline \multirow{2}{*}{ Religion } & Muslim & $24.80 \pm 3.03$ & $0.686(0.493)$ & $14.91 \pm 1.99$ & $0.397(0.692)$ \\
\hline & Hindu & $24.48 \pm 1.83$ & & $14.79 \pm 1.27$ & \\
\hline \multirow{2}{*}{ Employment status } & Unemployed & $24.76 \pm 2.86$ & $0.455(0.650)$ & $14.86 \pm 1.81$ & $-1.654(0.099)$ \\
\hline & Employee & $24.00 \pm 1.73$ & & $16.67 \pm 5.50$ & \\
\hline \multirow{2}{*}{ Number of children } & $<2$ & $24.61 \pm 2.76$ & $-0.542(0.588)$ & $14.97 \pm 1.93$ & $0.529(0.597)$ \\
\hline & $\geq 2$ & $24.81 \pm 2.88$ & & $14.84 \pm 1.83$ & \\
\hline \multirow{2}{*}{ Number of family member } & $<4$ & $24.43 \pm 3.11$ & $-0.754(0.451)$ & $14.88 \pm 1.91$ & $-0.057(0.955)$ \\
\hline & $\geq 4$ & $24.80 \pm 2.78$ & & $14.90 \pm 1.86$ & \\
\hline \multirow{2}{*}{ Monthly family income } & $<1000$ & $26.96 \pm 4.68$ & $4.30(<0.001)$ & $14.64 \pm 2.15$ & $-0.699(0.485)$ \\
\hline & $\geq 10000$ & $24.47 \pm 2.42$ & & $14.92 \pm 1.84$ & \\
\hline \multirow{2}{*}{ Length of pregnancy } & $<37$ wks & $24.50 \pm 2.11$ & $-0.527(0.598)$ & $15.94 \pm 2.88$ & $3.768(<0.001)$ \\
\hline & $\geq 37$ wks & $24.77 \pm 2.94$ & & $14.70 \pm 1.57$ & \\
\hline \multirow{2}{*}{ Complication during pregnancy } & Yes & $24.75 \pm 2.85$ & $0.638(0.524)$ & $14.84 \pm 1.81$ & $-2.607(0.010)$ \\
\hline & No & $24.00 \pm 2.00$ & & $16.83 \pm 3.19$ & \\
\hline
\end{tabular}

Table 3. Differences in awareness of antenatal care and impact of urban mothers' and newborn health according to demographic characteristics $(\mathrm{N}=201)$.

\begin{tabular}{|c|c|c|c|c|c|}
\hline \multirow{2}{*}{ Demographic characteristics } & \multirow{2}{*}{ Categories } & \multicolumn{2}{|c|}{ Maternal Awareness } & \multicolumn{2}{|c|}{ Impact of mothers' and newborn health } \\
\hline & & $\mathrm{M} \pm \mathrm{SD}$ & $\mathrm{t} / \mathrm{x}^{2}(\mathrm{p})$ & $\mathrm{M} \pm \mathrm{SD}$ & $\mathrm{t} / x^{2}(\mathrm{p})$ \\
\hline \multirow{2}{*}{ Age of mothers } & $<26$ yrs & $21.57 \pm 2.82$ & $0.590(0.556)$ & $14.23 \pm 1.88$ & $0.302(0.763)$ \\
\hline & $\geq 26 \mathrm{yrs}$ & $21.34 \pm 2.35$ & & $14.15 \pm 1.91$ & \\
\hline \multirow{2}{*}{ Education } & Illiterate & $22.62 \pm 3.63$ & $2.780(0.006)$ & $14.06 \pm 2.63$ & $-0.460(0.646)$ \\
\hline & Below college & $21.25 \pm 2.35$ & & $14.22 \pm 1.71$ & \\
\hline \multirow{2}{*}{ Religion } & Muslim & $21.47 \pm 2.59$ & $-0.275(0.783)$ & $14.29 \pm 1.80$ & $1.812(0.072)$ \\
\hline & Hindu & $21.63 \pm 3.13$ & & $13.54 \pm 2.43$ & \\
\hline \multirow{2}{*}{ Employment status } & Unemployed & $21.51 \pm 2.68$ & $0.490(0.625)$ & $14.28 \pm 1.84$ & $2.180(0.030)$ \\
\hline & Employee & $21.15 \pm 2.18$ & & $13.15 \pm 2.28$ & \\
\hline \multirow{2}{*}{ Number of children } & $<2$ & $21.54 \pm 2.95$ & $0.497(0.620)$ & $13.96 \pm 1.93$ & $-1.935(0.054)$ \\
\hline & $\geq 2$ & $21.35 \pm 2.24$ & & $14.48 \pm 1.73$ & \\
\hline \multirow{2}{*}{ Number of family member } & $<4$ & $21.15 \pm 1.73$ & $-1.146(0.253)$ & $13.92 \pm 1.92$ & $-1.361(0.175)$ \\
\hline & $\geq 4$ & $21.62 \pm 2.94$ & & $14.31 \pm 1.87$ & \\
\hline \multirow{2}{*}{ Monthly family income } & $<10000$ & $24.25 \pm 4.79$ & $3.873(<0.001)$ & $14.25 \pm 2.38$ & $0.105(0.916)$ \\
\hline & $\geq 10000$ & $21.30 \pm 2.36$ & & $14.19 \pm 1.86$ & \\
\hline \multirow{2}{*}{ Length of pregnancy } & $<37$ wks & $21.12 \pm 1.54$ & $-1.125(0.262)$ & $13.92 \pm 2.61$ & $-1.195(0.233)$ \\
\hline & $\geq 37$ wks & $21.60 \pm 2.92$ & & $14.29 \pm 1.57$ & \\
\hline \multirow{2}{*}{ Complication during pregnancy } & Yes & $21.53 \pm 2.72$ & $1.095(0.275)$ & $14.15 \pm 1.91$ & $-1.210(0.228)$ \\
\hline & No & $20.67 \pm 0.65$ & & $14.83 \pm 1.40$ & \\
\hline
\end{tabular}




\subsection{Differences in Urban Maternal Awareness of Antenatal Care and Impact of Mothers' and Newborn Health and Demographic Characteristics}

Table 3 shows urban mothers' awareness was statistically significantly different by education $(\mathrm{t}=2.780, \mathrm{p}$ 0.006) and monthly family income $(\mathrm{t}=3.873, \mathrm{p}<$ $0.001)$. Impact of mothers' and newborn health was statistically significant by employment status $(\mathrm{t}=2.180, \mathrm{p} 0.030)$.

\subsection{Differences among Maternal Awareness of ANC and Impact of Mothers' and Newborn Health}

Mothers' awareness on antenatal care and impact of mothers' and newborn health analyzed by descriptive statistics and t-test. The average awareness and impact score of rural mothers' was $18.54 \pm 2.77,9.41 \pm 2.13$ and highly significant different between awareness and impact was found $(\mathrm{t}=68.54, \mathrm{p}<0.001)$ and $19.69 \pm 2.16,9.39 \pm 2.25$ and it was also highly significant different between them $(\mathrm{t}=59.11, \mathrm{p}<0.001)$ among urban mother's (Table 4$)$.

\subsection{Relationship between Maternal Awareness of ANC and Impact of Mothers' and Newborn Health}

Table 5 Chi-square test analysis revealed that correlation between awareness of antenatal care and impact of mothers' and newborn health was found highly significant $\left(x^{2}=211.869, \mathrm{p} 0.004\right)$ among the rural mothers' and also highly significant found ( $x^{2}=157.772$, p 0.002) among the urban mothers'.

\section{Discussion}

The present study examined the maternal awareness of antenatal care on impact of mothers' and newborn health in Bangladesh. Two hundred forty one rural and two hundred one urban mothers' were recruited in this study. The present findings showed on behalf of rural mothers' awareness statistically significantly different only by monthly family income $(\mathrm{t}=4.30, \mathrm{p}<0.001)$ and on behalf of urban mothers' awareness was highly significant with education $(\mathrm{t}=2.780, \mathrm{p}$ $0.006)$ and monthly family income $(\mathrm{t}=3.873, \mathrm{p}<0.001)$. A study revealed

Table 4. Descriptive statistics independent t-test among maternal awareness and impact of mothers' and newborn health.

\begin{tabular}{cccr}
\hline \multirow{2}{*}{ Area } & \multicolumn{2}{c}{ Maternal Awareness } & \multicolumn{2}{c}{ Impact of Mothers' and Newborn health } \\
\cline { 2 - 4 } & $\mathrm{M} \pm \mathrm{SD}$ & $\mathrm{t}(\mathrm{p})$ & $\mathrm{M} \pm \mathrm{SD}(\mathrm{p})$ \\
\hline Rural mothers' & $18.54 \pm 2.77$ & $103.77(<0.001)$ & $9.41 \pm 2.13$ \\
Urban mothers' & $19.69 \pm 2.16$ & $128.91(<0.001)$ & $9.39 \pm 2.25$ \\
\hline
\end{tabular}

Table 5. Relationship between maternal awareness of antenatal care and impact of mothers' and newborn health.

\begin{tabular}{ccc} 
Variable & Area & $x^{2}$ \\
\hline \\
Maternal Awareness and impact of mothers and newborn health & Rural Mothers' & 211.869 \\
& Urban mothers' & 157.772 \\
\hline
\end{tabular}


antenatal care increases mothers' knowledge [27]. Generally rural mothers' having to more chance to share their knowledge with their relatives or neighbors. So their awareness did not significant different with their education. On behalf of urban mothers', it is difficult to do their share knowledge because of boundary living. For this awareness of urban mothers' was significant different with their education. Bangladesh is a developing and over populated country as compared to living place. In addition, per capita income is not standard as compared to developed countries.

Impact of mothers' and newborn health on maternal awareness of antenatal care was found significant different. The present study revealed that impact of rural mothers' and newborn health was statistically highly significant different by length of pregnancy $(\mathrm{t}=3.768, \mathrm{p}<0.001)$ and condition during pregnancy $(\mathrm{t}$ $=-2.607, \mathrm{p}$ 0.010). Impact of urban mothers' and newborn health was significantly different by employment status $(t=2.180, \mathrm{p} 0.030)$. Studies reported length of pregnancy is the most important for effective outcome of mother's and newborn health. Antenatal care module 13 revealed that quality of care is important and women perceptions of their care should be sought and considered to prevent complications during pregnancy at all stages [19] [28]. Length of pregnancy and condition during pregnancy of rural mother's was significant different with the impact of mothers and newborn health. Because mothers did not aware as they have low level education, besides this mother's have to depend with their family.

Bangladesh demographic health survey stated that the importance of ANC is the reduction of maternal morbidity and mortality by utilization of ANC services but remains low due to several factors contributing to the low utilization of antenatal care [29]. The present study showed that mother's awareness of ANC on impact of mother's and newborn heath was found statistically highly significant different $(\mathrm{t}=68.54, \mathrm{p}<0.001, \mathrm{t}=59.11, \mathrm{p}<0.001)$ among rural and urban mothers and also found significant correlation $\left(x^{2}=211.869, \mathrm{p} 0.004, x^{2}=\right.$ 157.772 , p 0.002). Proper antenatal care during pregnancy is very important to provide adequate advice and support to the woman and her family for developing healthy home behaviors and a birth and emergency preparedness plan to increase awareness of maternal and newborn health needs and self care during pregnancy, and the postnatal period, including the need for social support during and after pregnancy besides these preparing for early and exclusive breastfeeding and essential newborn care and considering the role of a supportive companion at birth [30] [31].

Health Population Nutrition Sector Development Program (HPNSDP) collaboration with the Ministry of Health and Family Welfare (MOHFW) initiated different program to be achieved the MDGs within five years from July 2011 to June 2016. Reduce child mortality and improve maternal health are the MDGs [14]. Antenatal care service is one of the programs which have been working to achieve the set target. The present study though found satisfactory findings regarding mother's awareness of ANC on impact of mother's and newborn health. 
But there have some limitations which did not meet the represent of whole population. So further community based intervention study necessary to represent the whole population in Bangladesh.

\subsection{Implications for Nursing Practice}

Nurse-midwife can provide adequate knowledge about antenatal care for pregnant mothers' on impact of mother's and newborn health. This study will help the Nurse-midwife for the prevention of pregnancy related problems and health promotion of mothers' and newborn health.

\subsection{Implications for Future Studies}

Future study is needed to identify the factors related to maternal antenatal care on mothers and newborn health with diverse setting. Further intervention study is also needed to evaluate the effect of intervention on maternal and child health outcomes. These may to improve mothers and newborn health in Bangladesh and also help to achieve the SDGs.

\subsection{Limitations}

Data were collected from two medical college hospitals. As a hospital based study, the results may not be generalized to whole population in Bangladesh.

\section{Conclusion}

This study demonstrated the implication of the antenatal care to assess the maternal awareness of antenatal care (ANC) on impact of mothers' and newborn health. The findings indicated that maternal' awareness of antenatal care on impact of mothers' and newborn health was statistically significant different both rural and urban mothers'. This study suggested that nurse-midwives can actively participate in facilitating information to support mothers' which may help to increase the mothers' awareness for better health outcomes for mothers and newborn in Bangladesh.

\section{Acknowledgements}

First of all, thanks to Allah S.W.T for giving me the strength to complete my study. Then gratitude my PhD Supervisor Dr. Md. Manjur Hossain, Assistant Professor, Dept. of Health \& Medical Science, American World University, USA. Sincere thanks to all postpartum mothers who participated in this study.

\section{References}

[1] Leontine, A., Doris, C., Daniel, H., Sanqian, Z., Moller, A.B., Alison, G., et al. (2016) Global, Regional, and National Levels and Trends in Maternal Mortality between 1990 and 2015, with Scenario-Based Projections to 2030: A Systematic Analysis by the UN Maternal Mortality Estimation Inter-Agency Group. Lancet, 387, 462-474. https://doi.org/10.1016/S0140-6736(15)00838-7

[2] WHO (2016) New Guidelines on Antenatal Care for a Positive Pregnancy Experience. Geneva. 
[3] Roy, A. and Shengelia, L. (2016) An Analysis on Maternal Health Care Situation in Bangladesh: A Review. Journal of Diversity \& Equality in Health and Care, 13, 360-364.

[4] WHO, UNICEF, UNFPA, World Bank Group, and the United Nations Population Division (2015) Trends in Maternal Mortality: 1990 to 2015. World Health Organization, Geneva.

[5] Statistics/Bangladesh/UNICEF: www.unicef.infobycountry/Bangladesh UNICEF Strategic Plan 2014-2017. https://www.unicef.org/strategicplan/.../UNICEF_Strategic_Plan_2014-2017_e-ver $\underline{\text { si }}$

[6] Countdown (2015) Maternal, Newborn and Child Survival. Fulfilling the Health Agenda for Women and Children, The 2014 Report.

[7] Nahar, S., Rahman, A. and Nasreen, H.E. (2013) Factors Influencing Stillbirth in Bangladesh: A Case Control Study. Paediatric and Perinatal Epidemiology, 27, 158-164. https://doi.org/10.1111/ppe.12026

[8] National Low Birth Weight Survey (2015) CIRDA Auditorium in Dhaka.

[9] Lawn, J., Cousens, S. and Zupan, J. (2005) Neonatal Survival Steering Team, 4 Million Neonatal Deaths: When? Why? Lancet, 365, 891-900. https://doi.org/10.1016/S0140-6736(05)71048-5

[10] Lozoff, B., Beard, J., Connor, J., Barbara, F., Georgieff, M. and Schallert, T. (2006) Long Lasting Neural and Behavioral Effects of Iron Deficiency in Infancy. Nutrition Review, 64, S34-S43. https://doi.org/10.1301/nr.2006.may.S34-S43

[11] Projahnmo (2008) Home Based Interventions in Bangladesh Show Significant Reduction in Neonatal Mortality.

[12] Maternal Mortality Affects Development of a Country (2015).

[13] Viengsakhone, L., Yoshida, Y., Harun, R.M.D. and Sakamoto, J. (2010) Factors Affecting Low Birth Weight at Four Central Hospitals in Vientiane, Lao PDR. Nagoya Journal Medical Science, 72, 51-58.

[14] Hashima, E., Nahar, K., Yvonne, F. and Maigun, E. (2010) Low Birth Weight in Offspring of Women with Depressive and Anxiety Symptoms during Pregnancy: Results from a Population Based Study in Bangladesh.

[15] Hossain, Q.A. (2009) Improving Food and Nutritional Status of the Poor, Marginal and Small Farmers through Farmers' Field School in Bangladesh. http://www.um.dk/NR/rdon/yres/5DBC6052

[16] ICNM (2015) Millennium Development Goals-Facts Sheet 2015. http://findgofind.co/search?q=Millennium\%20Development\%20Goals-facts\%20she et $\% 20(2015)$

[17] NIPORT (2011) Bangladesh Demographic Health Survey 2011. NIPORT, Mitra and Associates, Dhaka.

[18] Bangladesh Maternal Mortality Survey (2010).

[19] NIPORT, Measure Evaluation, UNC-CH, USA \& ICDDRB (2010) Bangladesh Maternal Mortality Survey and Health Survey 2010.

[20] Antenatal Care Module: 13 (2017) Providing Focused Antenatal Care Study. http://www.open.edu/openlearncreate/mod/oucontent/view.php?id=44\&printable= 1

[21] NIPPORT Ministry of Health and Family Welfare, Government of Bangladesh (2017) Bangladesh-Demographic Health Survey 2014. Dhaka. 
[22] NIPPORT Ministry of Health and Family Welfare, Government of Bangladesh (2013) Bangladesh Demographic Health Survey 2011. Dhaka.

[23] GED, Bangladesh Planning Commission, \& Governments of the People's Republic of Bangladesh (2013) Millennium Development Goals: Bangladesh Progress Report 2012. Dhaka.

[24] National Institute of Population Research and Training (NIPORT), MEASURE Evaluation, and ICDDRB (2012) Bangladesh Maternal Mortality and Health Care Survey 2010. Dhaka.

[25] Polit, D.F. and Beck, C.T. (2008) Nursing Research: Generating and Assessing Evidence for Nursing Practice. 8th Edition, Lippincott Williams \& Wilkins, Philadephia.

[26] PPRC and UNDP (16) An Emperical Study on Politics, Governance and Middle Income Aspirations. Realities and Challenges. Bangladesh 2016.

[27] Kadam, S. and Tata, S. (2012) Impact of Structured Education Programme on Antenatal Mothers Regarding Essential New Born Care. International Journal of Science and Research, 3, Article ID: 020131725. http://www.ijsr.net

[28] World Health Organization (2002) Essential Antenatal, Peri-Natal and Postnatal Care. Training Modules, Regional Office for Europe.

[29] Bangladesh Demographic Health Survey (2011).

[30] Shah, P., Hossain, M. and Erken, A. (2010) Certificate in Midwifery Curriculum-Six Month's Program for Registered Nurse-Midwives. Bangladesh Nursing Council.

[31] Dutta, D.C. (2014) Text Book of Obstetrics. 9th Edition. 